\title{
The Demand Analysis of Green Food in E-commerce
}

\author{
Saishuo Zheng \\ School of North China Electric Power University Baoding, Baoding 071000, China \\ 591039822@qq.com
}

Keywords: green food, demand analysis, SPSS, E-commerce, data analysis.

\begin{abstract}
Although green food have many benefits and have got many achievements, green food penetration and consumer awareness in China is not enough, and the E-commerce marketing strategy is not perfect at the same time. On the basis of these problems, this paper investigate customers' demand motivation through a questionnaire, including price, logistics, quality, safety, taste, experience new products, quality, environmental protection, consumer recommendations, customer service, service level, service attitude and business credit to analysis their relationship and what motivation is the most decisional by cross tabulation, correlation analysis, cluster analysis and factor analysis. After that, this paper provides some marketing strategies and E-commerce advice.
\end{abstract}

\section{Introduction}

After analyzing the investigation results of the E-commerce green food demand motivation questionnaire, we know the factors of consumer online shopping on green food. According to their consumption motivation, a precise marketing strategy can be set to make consumers have more satisfied green food and increase the satisfaction of E-commerce. The specific process of data analysis is shown as follows. As the first, from the consumer preference for green food types (such as fruits and cereals) to analyze the relationship of type selection and the personal information (including gender, age, occupation and education level) and find out what product factors are more important. After that, the consumers' consumption motivation have been divided into distinct kinds by cluster analysis. Then this paper use factors analysis to decrease the dimension. Finally, some reliable advice about green food E-commerce have been provided on the basis of questionnaire investigation results analysis.

\section{Organization of the text}

\section{Consumer personal information statistics and crosstab analysis results.}

From our investigation results, $36.2 \%$ of respondents prefer to buy green food fruits; $22.2 \%$ of respondents prefer to buy green food and beverage category; $15.9 \%$ of respondents prefer to buy green food tea; $12.1 \%$ of respondents prefer to buy green food cereals; $7.2 \%$ of respondents prefer to buy green food for livestock and poultry eggs; $6.3 \%$ of respondents prefer to buy green food aquatic products. To sum up, the respondents prefer to buy green food fruits, beverages and tea.

In order to investigate the relationship between the type of preference of green food and sex, occupation, age, education level and the understanding degree of green food, we got the second conclusion with the method of cross tabulation. The conclusion is shown as follows. First, the preference for grain and oil, fruits, aquatic products and beverages of man is more than women, but the preference for livestock, poultry eggs and tea is roughly equal between man and women. Second, as for the relation of preference and the occupation, there are 1 blue collar, 2 white collars, 2 gold collars, 1 civil servant, 2 retirees, accounted for $93.2 \%, 0.9 \%, 1.7 \%, 0.9 \%$ and $1.7 \%$, which shows the students are the most of our samples. When buying green food online, students and the gold collars prefer fruits and beverages, blue collars and white collars prefer fruits, civil servant prefer tea and the retirees prefer aquatic products, fruits and beverages.

As for the relation of preference and the age of respondents, people age under 18 prefer green tea and fruit products in the online green food shopping. People age 18-24 prefer fruits and beverages and people age 25-30 have partiality for fruits. Furthermore, people age 30-55 is partial 
to grain and oil and the 56 years old or older people prefer fruit, beverage and tea. According to the crosstab of preference and the education level, we can get the follow results. The people with college education background prefer fruits and beverages, the junior college education background prefer drinks and the people which education background is the master's degree or above prefer tea. What's more, as for the understanding degree of green food, the respondents who understand green food in general is the most, accounting for $80.7 \%$; the respondents who is familiar with green food is the second, accounting for more than $24.8 \%$ and the respondents who don't understand green food is the least, only accounting for $10.3 \%$. As a result, it can be seen that the consumers' awareness of green food is not enough, it will affect their green food consumption, so the E-commerce supplier in the green food page can strengthen the promotion of green food knowledge to increasing consumers' understanding for green food to tap the potential customers.

Analysis in like manner, the results about consumer motivation can be obtained that: People who have the motivation to experience new products tend to buy fruit, beverage and tea; The people who have motivation that green food is more health tend to grain and oil, fruits and beverages; The people who purchase green food for its good customer service tend to purchase fruits, drinks and tea; The people who purchase green food for its better quantity tend to purchase beverages, fruits and tea and people purchase it for its better taste, pursuing consumption grade and environmental friendly also tend to fruits, drinks and tea, the same with people who purchase green food just due to their friends' introduction, lower price and the faster logistics time. People who purchase green food online with considering the business credit, service quantity and the business service attitude tend to buy fruits and beverages most, the fewer cereals and tea and the fewest aquatic products, livestock and poultry eggs.

\section{Consumer demand motivation classification.}

To analysis different consumption motivations how to affect distinct people to purchase green food, we use cluster analysis to divide different motivation into different classification. The specific classification results is shown as follows.

From the figure 1, the 19 different demand motivation have been divided into 7 distinct classification. The first kind is the experience. The second kind is the safer, customers service, good quantity, good taste and the environmental friendly. The third kind is pursuing the consumption taste. The fourth kind is the logistic time and the fifth kind is the recommend of relatives and friends. The sixth kind is the business credit, service attitude and service quantity and the final kind is the price. 


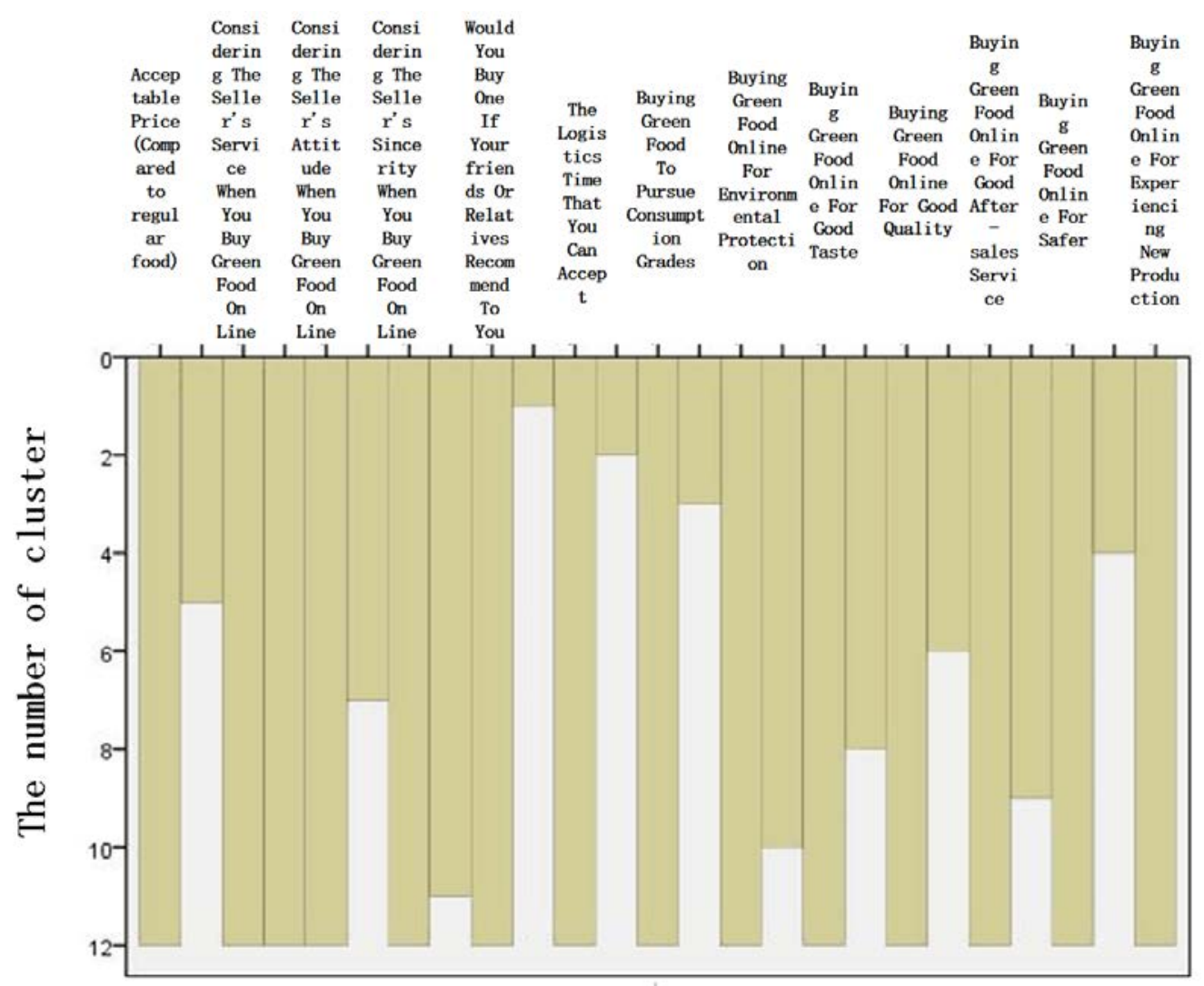

Fig. 1. The results of cluster analysis

\section{Factor analysis of different motivations.}

First of all, to check whether can we use the factor analysis to research the affects and relationship of the motivations, we tested the KMO and Bartlett sphericity. It can be seen from the results that the observation value of Bartlett sphericity test statistic is 531.946, and the corresponding probability is close to 0 , and the $\mathrm{KMO}$ value is about 0.771 . According to the KMO standard given by Kaiser, it can be applied to the factor analysis. Then we use SPSS to carry on the principal component analysis to it, and has drawn out its gravel figure as shown below.

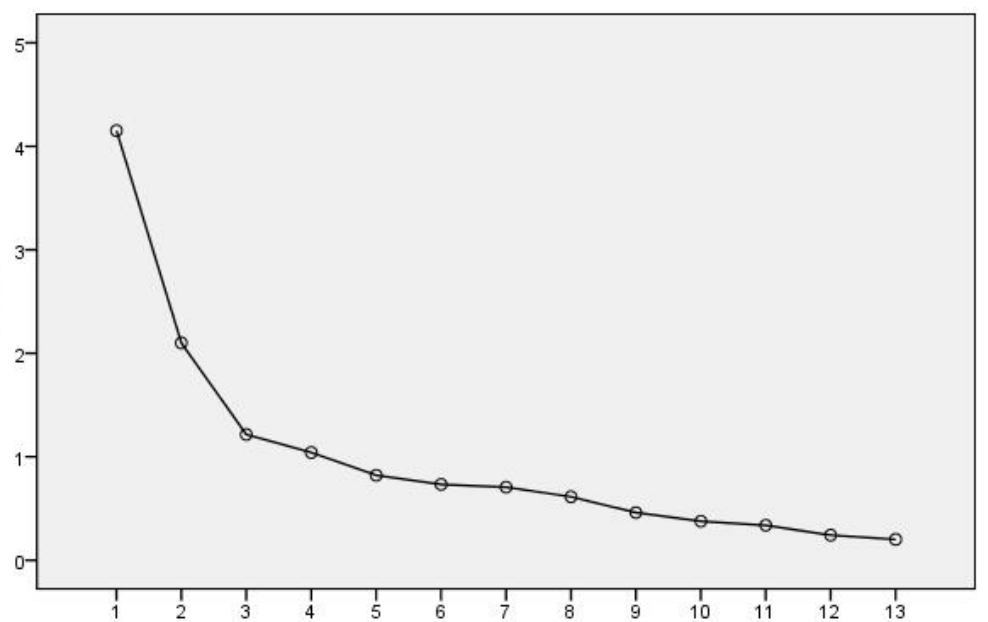

Fig. 2. The Scree plot results

The figure shows the characteristics of the first factor value is very high, and the contribution to explain the original variables is the largest. But the characteristics of factors after 4 is small, the same with its contribution, which has been a neglected "mountain at the foot of the stone". As a consequence, we take 4 factors only. Using SPSS, we can obtain some results that all of the 13 factors' load on the first basic factors are very high, which means that all of them is more related 
with the first factor and the first factor is the most important factor. However, the other 3 factors can’t explain the original variables significant.

\section{Summary}

On the basis of the analysis above, all of the 13 factors can be divided into four kinds, which contains quantity factors, business service factors, logistics time factors and the recommendation factors. On the fundamental analysis, we can give some advice as follows.

First of all, the business should be more detailed and accurate in the details of the introduction of these motivation factors. At the same time, At the same time, businesses should pay more attention to service attitude and service level, in order to improve the customer's shopping quality. Second, business can select goods with some special character to sell by their type, such as: as for the aquatic products of green food, the platform should provide some goods have price advantages and as for livestock and poultry eggs and green food, the platform should select sell the more safe goods with faster logistics. Third, because the green food motivation is significant related to motivation, all platforms can be timely promotion of green food content display and update. What's more, the platforms can sell goods with distinct advantages for distinct people, such as: for a psychological crowd, the business can recommend some new green food. For those who have the psychological security of the crowd, you can recommend some safety food. For people who have a quick mentality, in order to make them as much as possible to buy green food online, the site should be recommended in the selection of goods logistics fast recommendation.

\section{References}

[1] Norusis M. SPSS 15.0 Guide to Data Analysis[J]. Development Bulletin, 2007, 49(7):397-400.

[2] Guo, Zhigang. Social statistical analysis: SPSS software application [M]. Renmin University of China press, 2015

[3] Zhang Wentong, Dong Wei. SPSS advanced course of statistical analysis [M]. higher education press, 2013 